\title{
Screening of Microwave-Assisted-Batch Extraction Parameters for Recovering Total Phenolic and Flavonoid Contents from Chromolaena odorata Leaves through Two-Level Factorial Design
}

\author{
Oluwaseun Ruth Alara ${ }^{1,2, *}$, Abdurahman Hamid Nour ${ }^{1,2}$, and Siti Kholijah Abdul Mudalip ${ }^{2}$ \\ ${ }^{1}$ Centre of Excellence for Advanced Research in Fluid Flow (CARIFF), Universiti Malaysia, \\ Pahang, Lebuhraya Tun Razak, 26300 Gambang, Pahang, Malaysia \\ ${ }^{2}$ Faculty of Chemical and Natural Resources Engineering, Universiti Malaysia Pahang, \\ Lebuhraya Tun Razak, 26300 Gambang, Pahang, Malaysia
}

\section{* Corresponding author:}

tel: +601116543727

email: ruthoalao@gmail.com

Received: August 3, 2018

Accepted: December 13, 2018

DOI: $10.22146 / \mathrm{ijc} .40863$

\begin{abstract}
Microwave-assisted-extraction (MAE) of phenolic compounds from Chromolaena odorata leaves was investigated using one-factor-at-a-time (OFAT) and two-level factorial design. The MAE parameters studied were irradiation time (A: $1-5$ min); microwave power level (B: 400-800 W); extraction temperature (C: $\left.60-80{ }^{\circ} \mathrm{C}\right)$; solvent/feed ratio ( $D: 8: 1-14: 1 \mathrm{~mL} / \mathrm{g}$ ); and ethanol concentration (E: 20-60\% v/v). The optimum yields of TPC and TFC were $56.13 \mathrm{mg} \mathrm{GAE} / \mathrm{g}$ d.w. and $44.78 \mathrm{mg} \mathrm{QE} / \mathrm{g}$ d.w., respectively were achieved from MAE of C. odorata leaf at irradiation time of $2 \mathrm{~min}$, microwave power of $600 \mathrm{~W}$, temperature of $60^{\circ} \mathrm{C}$, solvent:feed ratio of 10:1 $\mathrm{mL} / \mathrm{g}$, and ethanol concentration of $40 \% \mathrm{v} / \mathrm{v}$ through one-factor-at-time (OFAT) experimental trials. The results obtained from a two-level factorial design experiments demonstrated that only ethanol concentration (20-60\% v/v), irradiation time (1-5 min) and microwave power level (400-800 W) had significant effects on the yields of total phenolic content (TPC) and total flavonoid content (TFC) from C. odorata leaves $(p<0.05)$. However, temperature and solvent/feed ratio was not significant. In addition, the interactions $A B$ (irradiation time and microwave power) and $A E$ (irradiation time and ethanol concentration) contributed greatly to the recovery yields.
\end{abstract}

Keywords: Chromolaena odorata; phenolics; flavonoids; microwave-assisted extraction

\section{- INTRODUCTION}

Over the few decades, studies on functional foods have increased, leading to the discovery of new bioactive components that can boost food processing and lead the reduction in oxidative-stress diseases. Plants are the source of natural phytochemicals such as secondary metabolites which are important as part of the food supplement and pharmaceutical active ingredients. Phenolics and flavonoids are important parts of secondary metabolites that can inhibit free radicals cells and minimize the possibility of cancer [1]. A lot of pharmacological activities which include antioxidant, anti-inflammatory, anti-diabetes, anti-microbial, and among others could be associated with the occurrence of phenolic compounds [2-4].

Chromolaena odorata, known to be bush bitter, is an invasive shrub widely found in sub-tropical regions of the world. This plant had been studied to be full of potentials as a medicinal shrub. In fact, it has been reported to improve soil properties, act as good phytoremediating and bioremediating agent against crude oil polluted soils [5]. The leaves are rich in carbohydrate, proteins, fiber, ash, and energy. Traditionally, this plant has been exploited as a source of medicine in the treatment of several ailments such as the human small cell, lungs, and breast cancer, inflammation, and burn wounds intestine diseases [5-6].

Oluwaseun Ruth Alara et al. 
Different phenolic compounds had been isolated from $C$. odorata leaves, including $p$-coumaric, vanillic acids, protocatechuic, quercetin, kaempferol, luteolin, and others, which can reduce the oxidative degradation of lipids [7]. Phenolic compounds are known to possess antioxidant activity through various mechanisms, including free radical inhibition, hydrogen donors, metal chelation, gene expression, and signaling pathways [8]. Different extraction methods had been employed in previous studies to recover phenolic compounds from this plant, which include maceration, decoction and Soxhlet [7,9-10]. Nevertheless, lower recovery yields of the phenolic compounds had been reported through these conventional extraction methods. Therefore, microwaveassisted extraction method has been employed in this study for higher recoveries of phenolic compounds from C. odorata leaves.

Microwave-assisted-extraction (MAE) is a modern method with the advantage of recovering higher yield of phenolic compounds from plant matrix within a shorter irradiation time and a small amount of solvent [11]. Comparing to other unconventional extraction methods, such as ultrasonic-assisted-extraction, MAE can recover higher yield faster than other methods [12]. Nevertheless, different factors including extraction temperature, solvent/feed ratio, irradiation time, the concentration of solvent, and microwave power can alter the performance of MAE [13]. The efficiency of MAE had been previously compared with ultrasound-assisted-and conventional solvent extraction of TPC from Pistacia lentiscus leaves. The results reflected that MAE gave TPC in higher yield of comparing to the other two extraction methods [12]. In addition, MAE had been previously employed to recover TPC and TFC from Vernonia cinerea leaves. The results indicated that higher yields of phenolic compounds can be achieved through MAE [14]. To the best of our knowledge, there is no study on the application of MAE in the recovery of TPC and TFC from C. odorata leaves had been found.

MAE is influenced by several parameters which include microwave power, temperature, feed/solvent ratio, solvent concentration, and irradiation time. In order to determine the ranges of value for these parameters, one-factor-at-a-time experimental trials are usually used by varying one parameter when keeping the others fixed [13]. However, to affirm the significant contribution of individual extraction parameter, the two-level factorial design is mostly employed. Therefore, this study focuses on the use of a two-level factorial design in filtering the MAE variables to determine the contribution of individual variables in the recoveries of total phenolic and flavonoid contents from C. odorata leaves, the ranges for individual MAE variables were determined through single factor experiment.

\section{- EXPERIMENTAL SECTION}

\section{Materials and Chemicals}

The leaves of C. odorata were harvested from Universiti Malaysia Pahang, Gambang premises. The sample was rinsed using running tap water to eliminate earth debris and air-dried to achieve a stable weight. Then, the dried leaves were blended using an electric grinder and kept in a sealed dark container at $4{ }^{\circ} \mathrm{C}$ prior to the extraction process. The average moisture content of the sample before extraction was estimated to be $0.017 \pm 0.03 \mathrm{~g}$ water/ dry sample.

Quercetin, anhydrous aluminum chloride, FolinCiocalteu phenol reagent, sodium carbonate salt, and ethanol (99 wt.\% purity), and gallic acid were purhased from Sigma-Aldrich (M) Sdn Bhd, Selangor.

\section{Procedure}

\section{Microwave-assisted-extraction}

The ranges of MAE variables, including microwave power level (200-800 W); extraction temperature (40$\left.100{ }^{\circ} \mathrm{C}\right)$; irradiation time $(1-20 \mathrm{~min})$; ethanol concentration (20-80\% v/v); and solvent/feed ratio (6:1$16: 1 \mathrm{~mL} / \mathrm{g}$ ) were randomly examined using a one-factorat-a-time experiment (Fig. 1) [13]. The crushed sample of $C$. odorata leaves $(5 \mathrm{~g})$ was mixed with the binary mixture of ethanol and water based on the single factor and two-level experimental design matrix (Fig. 1, Table 1). The suspension was placed in an enclosed Milestone microwave reflux extractor (ATC-FO-300 model, N. America). The single factor experiment was carried out by changing the values of a factor and fixing others 

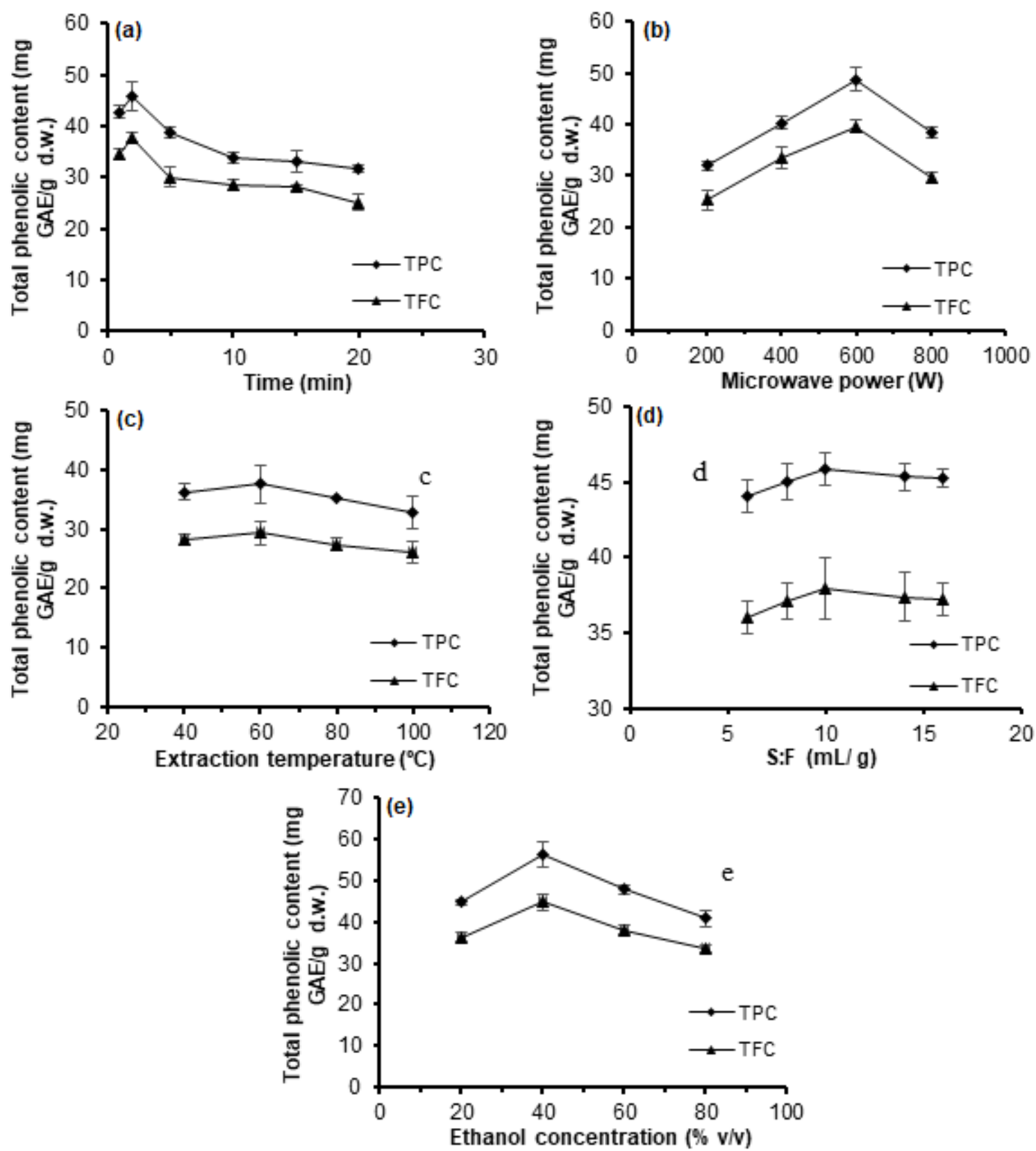

Fig 1. Influence of irradiation time (a), microwave power (b), extraction temperature (c), solvent/feed ratio (d), and ethanol concentration (e) on the TPC and TFC yields from C. odorata leaves

constantly. In the case of irradiation time, the variation was randomly ranged from 1 to $20 \mathrm{~min}$, while keeping solvent/feed ratio, microwave power, extraction temperature, and ethanol concentration at $6: 1 \mathrm{~mL} / \mathrm{g}$, $200 \mathrm{~W}, 40{ }^{\circ} \mathrm{C}$, and $20 \% \mathrm{v} / \mathrm{v}$, respectively. The suspension was filtered and dried using a rotary evaporator. Thereafter, the extracts were analyzed to determine TPC and TFC recovery yields.

\section{Total phenolic content determination}

TPC in the C. odorata leaf extract was determined according to the procedure employed in a previous study [15]. The TPC was calculated using Eq. (1). For the purpose of error correction, the analysis was done in triplicate and the obtained results were expressed as mean \pm standard deviation. 
TPC $(\mathrm{mg} \mathrm{GAE} / \mathrm{g}$ d.w. $)=\frac{\text { Conc. }(\mathrm{mg} / \mathrm{mL}) \times \text { vol. of solvent used }(\mathrm{mL})}{\text { Weight of dried sample used }(\mathrm{g})}$

\section{Evaluation of total flavonoid content}

Total flavonoid content in the C. odorata leaf extract was determined using the procedure used in a previous study [15]. Then, TFC was calculated using Eq. (2). The analysis was repeated thrice, and the obtained results were reported as mean \pm standard deviation.

$\mathrm{TFC}(\mathrm{mg} \mathrm{QE} / \mathrm{g}$ d.w. $)=\frac{\text { Conc. }(\mathrm{mg} / \mathrm{mL}) \times \text { vol. of solvent used }(\mathrm{mL})}{\text { Weight of dried sample used }(\mathrm{g})}$

\section{Statistical analysis}

In order to examine the effect of five MAE variables, a two-level half factorial experimental design with 16 runs was employed. Each run was carried out thrice to determine the experimental error. The resulting data and statistical analysis were evaluated using Design Expert 7.0 software $^{\circledast}$ (Minneapolis, USA) and Microsoft Excel 2013 .

\section{- RESULTS AND DISCUSSION}

\section{One-factor-at-a-time Experiment}

The one-factor-at-a-time experiments were carried out to evaluate the effect of each MAE variable on the TPC and TFC yields from C. odorata leaf and to determine the range limit at which the experimental processes need to be performed. Five MAE factors, including microwave power level, extraction temperature, irradiation time, ethanol concentration, and solvent/feed ratio were considered. Basically, this experimental process was performed by changing the values of a parameter while others were fixed.

For the irradiation time variation, microwave power $(200 \mathrm{~W})$, extraction temperature $\left(40{ }^{\circ} \mathrm{C}\right)$, solvent/feed ratio $(6: 1 \mathrm{~mL} / \mathrm{g})$, and ethanol concentration $(20 \% \mathrm{v} / \mathrm{v})$ were fixed at various irradiation time between 1 and $20 \mathrm{~min}$ (Fig. 1(a)). The irradiation time is one of the main factors that affect MAE. It can be seen that an improvement in the irradiation time from 1 to $2 \mathrm{~min}$ was followed by the increase in TPC and TFC. Beyond 2 min of irradiation, the yields gradually decrease which implies that final equilibrium had been achieved between the solute concentration in the plant materials and bulk solution as explained by Fick's second law of diffusion [16]. Thus, excessive irradiation time was unnecessary to extract phenolic compounds from C. odorata leaves. In addition, prolonged extraction might degrade the phenolic compounds due to oxygen exposure. Considering this fact, irradiation time at the range of 1 to $5 \mathrm{~min}$ was selected for the two-level factorial design experimental processes.

The selection of microwave power levels is another important variable in MAE. Microwave power level was varied between 200 to $800 \mathrm{~W}$ at fixed irradiation time of 2 min, extraction temperature of $40{ }^{\circ} \mathrm{C}$, the solvent/feed ratio of $8: 1 \mathrm{~mL} / \mathrm{g}$, and ethanol concentration of $20 \% \mathrm{v} / \mathrm{v}$. Fig. 1(b) illustrates the influence of microwave power on TPC and TFC. There was a noticeable increase in the TPC and TFC recoveries as microwave power level improved from 200 to $600 \mathrm{~W}$, prolong increase in power decline the yield recoveries. This might be due to the thermal degradation of phenolic compounds at elevated microwave power [17]. Therefore, a range of $400-800 \mathrm{~W}$ microwave power level was chosen for further experimentation.

The influences of extraction temperature on MAE of TPC and TFC from C. odorata leaf are illustrated in Fig. 1(c). TPC and TFC slightly increased as the extraction temperature increased from 40 to $60{ }^{\circ} \mathrm{C}$. There was an insignificant increment in the yields as the extraction temperature increases. This implies that extraction temperature might have little or no effects on the recovery of phenolic compounds from $C$. odorata leaves using MAE. More so, it should be noted that increasing extraction temperature beyond a certain limit may cause concurrent degradation of phenolic compounds that would have been mobilized at a lower temperature. Likewise, a higher extraction temperature leads to solvent loss through vaporization, this can increase the cost of the extraction process $[10,12]$. In order to affirm the significant contribution of extraction temperature to this process, the extraction temperature in a range of 40 to $80{ }^{\circ} \mathrm{C}$ was chosen for further experimentation.

Similarly, the effects of solvent/feed ratio on MAE of phenolic compounds from C. odorata leaves at a constant microwave power level of $600 \mathrm{~W}$, the irradiation 
Table 1. Experimental design matrix using two-level factorial

\begin{tabular}{|c|c|c|c|c|c|c|c|}
\hline \multirow[t]{2}{*}{ Run } & \multicolumn{5}{|c|}{ Variables } & \multicolumn{2}{|c|}{ Responses } \\
\hline & A & B & $\mathrm{C}$ & $\mathrm{D}$ & $\mathrm{E}$ & $\mathrm{Y}_{1}$ & $\mathrm{Y}_{2}$ \\
\hline 1 & 1 & 400 & 40 & $8: 1$ & 60 & 68.02 & 43.55 \\
\hline 2 & 5 & 400 & 40 & $8: 1$ & 20 & 65.02 & 40.12 \\
\hline 3 & 1 & 800 & 40 & $8: 1$ & 60 & 50.00 & 26.34 \\
\hline 4 & 5 & 800 & 40 & $8: 1$ & 60 & 53.49 & 28.09 \\
\hline 5 & 1 & 400 & 80 & $8: 1$ & 20 & 54.18 & 34.65 \\
\hline 6 & 5 & 400 & 80 & $8: 1$ & 60 & 66.43 & 44.43 \\
\hline 7 & 1 & 800 & 80 & $8: 1$ & 60 & 66.97 & 45.11 \\
\hline 8 & 5 & 800 & 80 & $8: 1$ & 20 & 53.15 & 31.96 \\
\hline 9 & 1 & 400 & 40 & $14: 1$ & 20 & 51.00 & 32.01 \\
\hline 10 & 5 & 400 & 40 & $14: 1$ & 60 & 66.33 & 45.34 \\
\hline 11 & 1 & 800 & 40 & $14: 1$ & 60 & 77.85 & 56.99 \\
\hline 12 & 5 & 800 & 40 & $14: 1$ & 20 & 53.24 & 29.87 \\
\hline 13 & 1 & 400 & 80 & $14: 1$ & 60 & 67.03 & 43.02 \\
\hline 14 & 5 & 400 & 80 & $14: 1$ & 20 & 65.88 & 42.45 \\
\hline 15 & 1 & 800 & 80 & $14: 1$ & 20 & 54.86 & 30.25 \\
\hline 16 & 5 & 800 & 80 & $14: 1$ & 60 & 43.15 & 21.09 \\
\hline
\end{tabular}

A - Irradiation time (min); B - Microwave power (W); C - Temperature $\left({ }^{\circ} \mathrm{C}\right) ; \mathrm{D}$ - Solvent/feed ratio $(\mathrm{mL} / \mathrm{g}) ; \mathrm{E}$ - Ethanol concentration (\% v/v); $Y_{1}$ - Total phenolic content (mg GAE/g d.w.); $Y_{2}$ - Total flavonoid content (mg QE/g d.w.); d.w. - dry weight

time of $2 \mathrm{~min}$, extraction temperature of $60^{\circ} \mathrm{C}$, and $20 \%$ $\mathrm{v} / \mathrm{v}$ of ethanol concentration are shown in Fig. 1(d). It can be observed that gradual increase in TPC and TFC only occurred when solvent/feed ratio was increased from 6:1 to $10: 1 \mathrm{~mL} / \mathrm{g}$, there was an insignificant increase in yield as the volume of the extracting solvent increased beyond 10:1 mL/g. In general, the solvent/feed ratio showed little or no influence on the recovery of phenolic compounds from C. odorata leaves. The two-level factorial design was further employed to confirm the contributing level of solvent/feed ratio to the recoveries of TPC and TFC from C. odorata leaf. Thus, the recovery of TPC and TFC was maximized at a solvent/feed ratio of $10: 1 \mathrm{~mL} / \mathrm{g}$. The ratio of $8: 1-14: 1 \mathrm{~mL} / \mathrm{g}$ was selected for the two-level full factorial experiments.

The influences of ethanol concentration on the TPC and TFC yields from MAE of C. odorata leaves are presented in Fig. 1(e). Ethanol concentration was varied between 20 and $80 \% \mathrm{v} / \mathrm{v}$ at fixed irradiation time of $2 \mathrm{~min}$, $600 \mathrm{~W}$ microwave power, extraction temperature of $60^{\circ} \mathrm{C}$, and solvent/feed ratio of $10: 1 \mathrm{~mL} / \mathrm{g}$. Increase in phenolic compounds was observed as the ethanol concentration inclined from 20 to $40 \% \mathrm{v} / \mathrm{v}$ followed by a reduction in yields (ethanol concentration beyond $40 \% \mathrm{v} / \mathrm{v}$ ). The optimum yields of TPC and TFC were $56.13 \mathrm{mg} \mathrm{GAE} / \mathrm{g}$ d.w. and $44.78 \mathrm{mg} \mathrm{QE} / \mathrm{g}$ d.w., respectively were achieved from MAE of C. odorata leaf at irradiation time of $2 \mathrm{~min}$, microwave power of $600 \mathrm{~W}$, the temperature of $60^{\circ} \mathrm{C}$, S:F ratio of $10: 1 \mathrm{~mL} / \mathrm{g}$, and ethanol concentration of $40 \%$ $\mathrm{v} / \mathrm{v}$. A similar effect has been reported for the extraction of phenolic compounds from Pistacia lentiscus leaves, increasing ethanol concentration beyond $50 \% \mathrm{v} / \mathrm{v}$ resulted in drastic reduction of phenolic compounds [12]. This study revealed that $100 \% \mathrm{v} / \mathrm{v}$ absolute ethanol can not recover higher phenolic compounds as compared with aqueous ethanol. This phenomenon can simply be explained based on the fact that molecular movement and solvent polarity tends to decrease as the ethanol concentration increases, which result in the reduced dissolution of phenolic compounds due to the declined solubility and diffusion coefficient [12]. The range between 20 and $60 \% \mathrm{v} / \mathrm{v}$ was selected for further experimentation. 
Table 2. ANOVA and contributing level of each MAE factor and p-values for the responses

\begin{tabular}{|c|c|c|c|c|}
\hline \multirow{2}{*}{$\begin{array}{l}\text { MAE } \\
\text { variables }\end{array}$} & \multicolumn{2}{|c|}{ Percentage contribution (\%) } & \multicolumn{2}{|c|}{$\mathrm{p}$-values for the responses } \\
\hline & $\mathrm{Y}_{1}$ & $\mathrm{Y}_{2}$ & $\mathrm{Y}_{1}$ & $\mathrm{Y}_{2}$ \\
\hline Model & & & 0.0006 & 0.0004 \\
\hline A & 2.63 & 3.90 & 0.0139 & 0.0044 \\
\hline B & 12.77 & 14.93 & 0.0008 & 0.0003 \\
\hline $\mathrm{C}$ & 0.86 & 0.42 & 0.0748 & 0.1300 \\
\hline $\mathrm{D}$ & 0.021 & 0.22 & 0.7271 & 0.2406 \\
\hline $\mathrm{E}$ & 18.71 & 17.21 & 0.0004 & 0.0003 \\
\hline $\mathrm{AB}$ & 23.95 & 21.34 & & \\
\hline $\mathrm{AC}$ & 0.16 & 0.027 & & \\
\hline $\mathrm{AD}$ & 2.16 & 1.63 & & \\
\hline $\mathrm{AE}$ & 29.46 & 24.03 & & \\
\hline $\mathrm{BC}$ & 1.87 & 1.29 & & \\
\hline $\mathrm{BD}$ & 0.39 & 0.21 & & \\
\hline $\mathrm{BE}$ & 0.011 & 0.16 & & \\
\hline $\mathrm{CD}$ & 2.30 & 9.88 & & \\
\hline $\mathrm{CE}$ & 4.66 & 4.68 & & \\
\hline $\mathrm{DE}$ & 0.049 & 0.067 & & \\
\hline
\end{tabular}

A - Irradiation time (min); B - Microwave power (W); C - Temperature $\left({ }^{\circ} \mathrm{C}\right)$; D- Solvent/feed ratio (mL/g); E Ethanol concentration (\% v/v); $\mathrm{Y}_{1}$ - Total phenolic content (mg GAE/g d.w.); $\mathrm{Y}_{2}$ - Total flavonoid content (mg QE/g d.w.); d.w. - dry weight

Influence of MAE Parameters on the TPC and TFC Yields from $C$. odorata Leaf Extract Using a TwoLevel Full Factorial Design

The influences of five MAE variables such as irradiation time; extraction temperature; solvent/feed ratio; ethanol concentration, and microwave power on the yields of TPC and TFC from C. odorata leaves were examined using the two-level half factorial design. The evaluation of five MAE variables required a total number of 16 experimental trials (Table 1). The effects of individual variable and their interactions on the recovery yields were determined based on the percentage of their contributions and significant levels at $\mathrm{p}<0.05$. Table 2 illustrates the ANOVA and percentage contribution of each variable alongside their interactions. It can be observed that the models for both responses are significant with the p-value less than 0.05. Ethanol concentration (E) was the most contributing factors with 18.71 and $17.21 \%$ for TPC and TFC, respectively while the solvent/feed ratio was the least contributing factor. This indicates that ethanol concentration is more important in the recovery if TPC and TFC from C. odorata leaves as it had the most significant influence on yields with the highest percentage of contribution. This phenomenon can simply be explained based on the fact that molecular movement and solvent polarity tends to decrease as the ethanol concentration increases, which result in the reduced dissolution of phenolic compounds due to declined solubility and diffusion coefficient [12].

Likewise, the ethanol concentration, irradiation time and microwave power had noticeable influences on the responses $(\mathrm{p}<0.05)$, however, solvent/feed ratio and extraction temperature were insignificant. The higher contributing levels of irradiation time, ethanol concentration and microwave power had been previously reported for MAE of Reb-A, stevioside and total extract from Stevia rebaudiana leaves [19]. The contribution level of individual variables is in order of ethanol concentration > microwave power level > irradiation time $>$ temperature $>$ solvent/feed ratio. However, the interaction between variables as well accorded to the recoveries of TPC and TFC from $C$. odorata leaf. From the obtained results, the interactions between irradiation time and microwave power, 

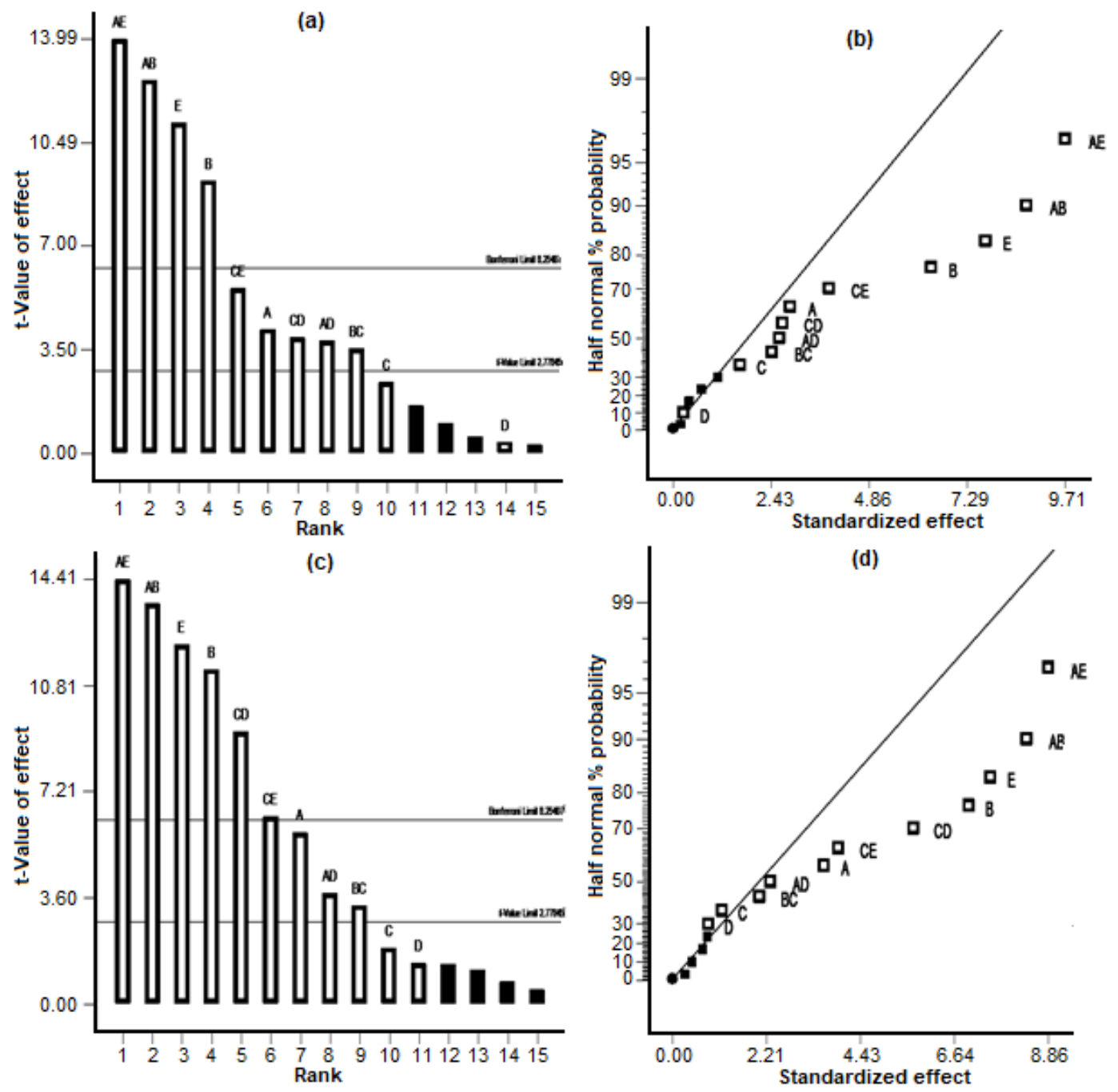

Fig 2. Pareto and half normal probability plots for the recovery of TPC ( $a$ and $b$ ) and TFC (c and d)

irradiation time and ethanol concentration greatly contributed to the yields of TPC and TFC. It has been reported that solvent concentration, irradiation time and microwave power level are the main MAE variable that determines the quantity and quality of recovery yields from plant materials $[9,14-15]$. Thus, the interactions between these three MAE factors play important role in recovering TPC and TFC from C. odorata leaves. A related result had been obtained in the extraction of phenolic compounds from Vernonia amygdalina leaves [15]. Likewise, the obtained results from two-level factorial design were in line with the OFAT experiments (Fig. 1).

Moreover, Pareto and half normal probability plots shown in Fig. 2 are employed to compare the statistical significance of the MAE independent variables and their interaction terms on the TPC and TFC yields from $C$. odorata leaf. The sampling errors through the standard deviation of MAE variables are being measured using Pareto plot. From the plots, the effect of interactions between irradiation time $\mathrm{x}$ ethanol concentration and irradiation time $\mathrm{x}$ microwave power were the main contributing factors to the recoveries. Ethanol concentration was the most contributing parameter with a positive effect (Fig. 2). However, solvent/feed ratio and temperature were the least contributing factors. This indicates that temperature might have little or no effects on the recovery of phenolic compounds from C. odorata leaves using MAE. Moreover, it should be noted that increasing extraction temperature beyond a certain limit 

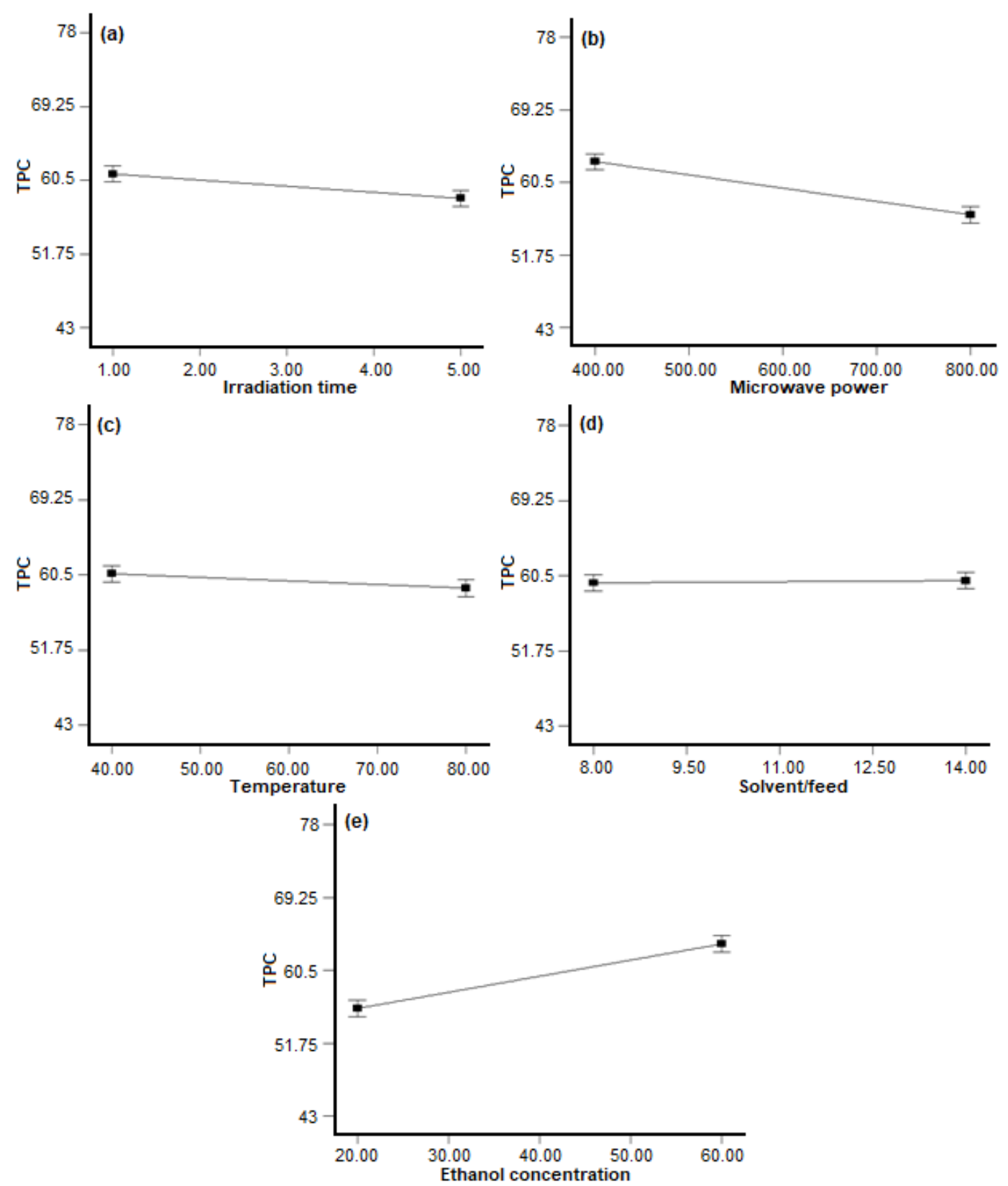

Fig 3. Effect of irradiation time (a), microwave power (b) temperature (c), solvent/feed ratio (d), and ethanol concentration (e) on the TPC yields from C. odorata leaf

may cause concurrent degradation of phenolic compounds that would have been mobilized at a lower temperature. A higher extraction temperature can results in solvent loss through vaporization, this can increase the cost of the extraction process $[10,12]$. Previous reports by Ameer et al. showed that the interaction between irradiation time and ethanol concentration, and irradiation time and microwave power enhanced the Reb-A from powdered stevia leaves [19].

In addition, half normal probability plots confirmed the outcome from Pareto charts. Insignificant variables with zero means and variances were distributed along the straight line of the plot while the significant ones were located at the right side of the plots 
according to their level of contribution. Thus, the contributing effect of main- and interaction terms to the recoveries of TPC and TFC were in order: $\mathrm{AE}>\mathrm{AB}>\mathrm{E}>$ $\mathrm{B}>\mathrm{CE}>\mathrm{A}>\mathrm{CD}>\mathrm{AD}>\mathrm{BC}$. Therefore, the three variables: irradiation time (1-5 $\mathrm{min})$, ethanol concentration (20$60 \% \mathrm{v} / \mathrm{v})$ and microwave power $(400-800 \mathrm{~W})$ at fixed temperature of $60^{\circ} \mathrm{C}$ and solvent/feed ratio of $10: 1 \mathrm{~mL} / \mathrm{g}$ are suggested for the optimization process using response
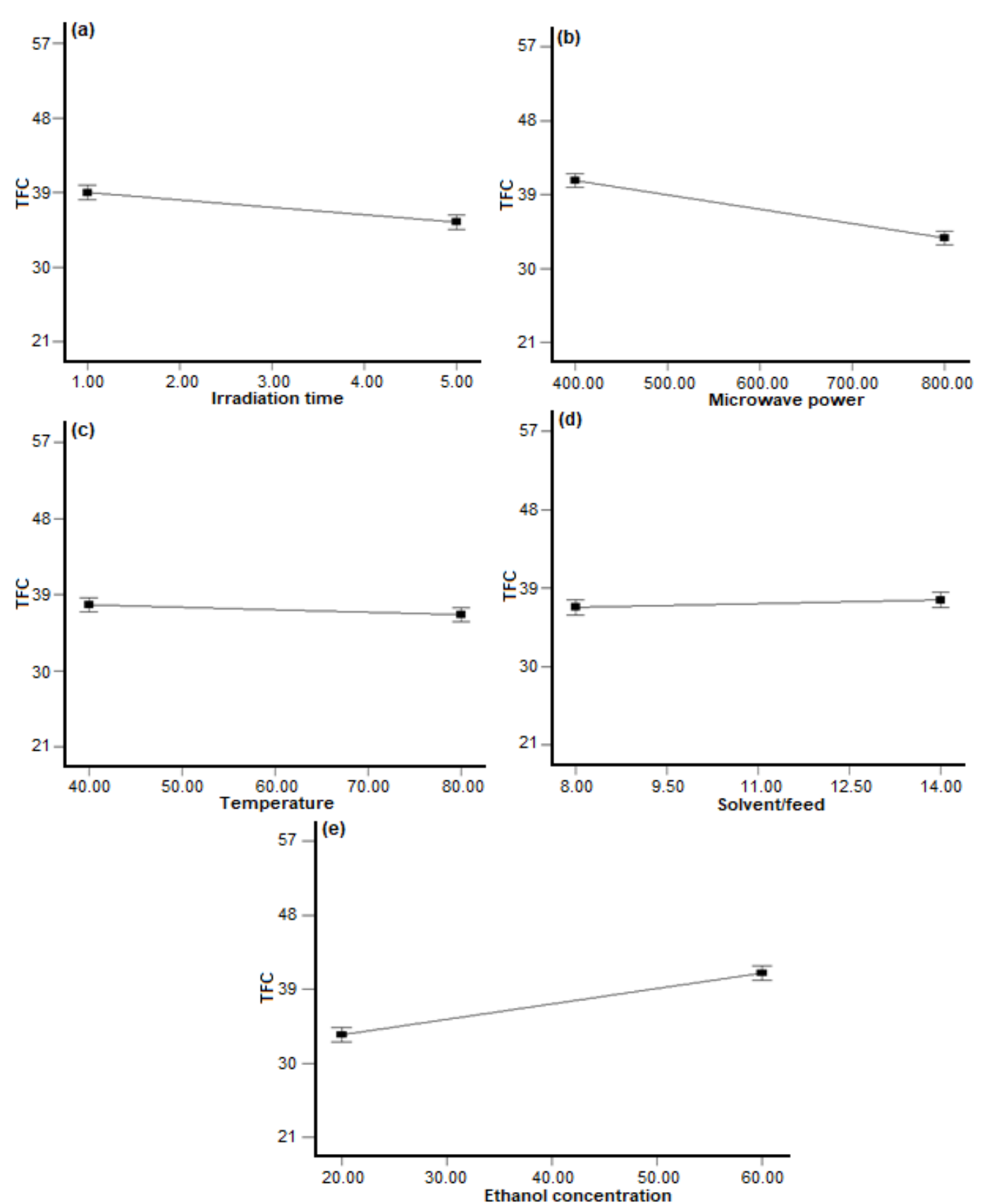

Fig 4. Effect of irradiation time (a), microwave power (b) temperature (c), solvent/feed ratio (d), and ethanol concentration (e) on the TFC yields from C. odorata leaf

Oluwaseun Ruth Alara et al.

surface methodology so as to obtain optimal recoveries of TPC and TFC from C. odorata leaves.

On the other hand, it can be observed that the TPC and TFC increase with increasing ethanol concentration to obtain the highest values of $63.66 \mathrm{mg} \mathrm{GAE} / \mathrm{g}$ d.w. and $40.95 \mathrm{mg}$ QE/g d.w., respectively at 3 min of irradiation time, microwave power of $600 \mathrm{~W}$, the temperature of $60{ }^{\circ} \mathrm{C}$, and solvent/feed ratio of $11: 1 \mathrm{~mL} / \mathrm{g}$ (Fig. 3 and 4). 
This showed that increasing ethanol concentration from 20 to $60 \% \mathrm{v} / \mathrm{v}$ improves the yields of TPC and TFC from C. odorata leaves. In contrast, the TPC and TFC yields declined with the increasing irradiation time and microwave power (Fig. 3 and 4). This can be associated with the influence of microwave power in degrading phenolic compounds at prolonging irradiation time [17]. Thus, increasing irradiation time from 1 through $5 \mathrm{~min}$ declined TPC from 61.24 to $58.34 \mathrm{mg} \mathrm{GAE} / \mathrm{g}$ d.w. and TFC from 38.99 to $35.42 \mathrm{mg} \mathrm{QE} / \mathrm{g}$ d.w., respectively. It can be clearly observed that varying temperature between 40 and $80{ }^{\circ} \mathrm{C}$, and solvent/feed ratio between $8: 1$ and $14: 1$ $\mathrm{mL} / \mathrm{g}$ only showed little variations in the yields of TPC and TFC which were not significant based on the ANOVA results with $\mathrm{p}>0.05$ (Table 2).

\section{- CONCLUSION}

The screening of MAE variables for the recoveries of TPC and TFC from C. odorata leaves was successfully achieved through a two-level factorial design. Effects of individual variables, including: irradiation time (1-5 min); temperature $\left(60-80{ }^{\circ} \mathrm{C}\right)$; microwave power $(400-800 \mathrm{~W})$; ethanol concentration $(20-60 \% \mathrm{v} / \mathrm{v})$; and solvent/feed ratio $(8: 1-14: 1 \mathrm{~mL} / \mathrm{g})$ showed that solvent/feed ratio and extraction temperature had unnoticeable effects on the recovery yields $(p>0.05)$. The optimum yields of TPC and TFC were $56.13 \mathrm{mg} \mathrm{GAE} / \mathrm{g}$ d.w. and $44.78 \mathrm{mg} \mathrm{QE} / \mathrm{g}$ d.w., respectively were achieved from MAE of $C$. odorata leaf at irradiation time of $2 \mathrm{~min}$, microwave power of 600 $\mathrm{W}$, temperature of $60^{\circ} \mathrm{C}$, solvent:feed ratio of $10: 1 \mathrm{~mL} / \mathrm{g}$, and ethanol concentration of $40 \% \mathrm{v} / \mathrm{v}$ through one-factorat-time (OFAT) experimental trials. Moreover, the interactions $\mathrm{AB}$ (irradiation time and microwave power) and $\mathrm{AE}$ (irradiation time and ethanol concentration) greatly contributed to TPC and TFC yields from $C$. odorata leaves. Thus, the significant variables which include microwave power (400-800 W), irradiation time (1-5 min) and ethanol concentration (20-60\%) at fixed temperature $\left(70^{\circ} \mathrm{C}\right)$ and solvent/feed ratio $(10: 1 \mathrm{~mL} / \mathrm{g})$ can be further optimized to achieve maximum yields of TPC and TFC from C. odorata leaves.

\section{- ACKNOWLEDGMENTS}

We thank the Universiti Malaysia Pahang for the technical and financial assistance through RDU180329 grant.

\section{- REFERENCES}

[1] Alara, O.R., Abdurahman, N.H., Ukaegbu, C.I., Azhari, N.H., and Kabbashi, N.A., 2018, Metabolic profiling of flavonoids, saponins, alkaloids, and terpenoids in the extract from Vernonia cinerea leaf using LC-Q-TOF-MS, J. Liq. Chromatogr. Related Technol., 41 (11), 722-731.

[2] Chen, A.Y., and Chen, Y.C., 2014, A review of the dietary flavonoid, kaempferol on human health and cancer chemoprevention, Food Chem., 138 (4), 2099-2107.

[3] Yao, L.H., Jiang, Y.M., Shi, J., Tomás-Barberán, F.A., Datta, N., Singanusong, R., and Chen, S.S., 2004, Flavonoids in food and their health benefits, Plant Foods Hum. Nutr., 59 (3), 113-122.

[4] Mihai, C.M., Mãrghitaş, L.A., Dezmirean, D.S., and Lavinia, B., 2011, Correlation between polyphenolic profile and antioxidant activity of propolis from Transylvania, Anim. Sci. Biotechnol., 44 (2), 100-103.

[5] Omokhua, A.G., McGaw, L.J., Finnie, J.F., and Van Staden, J., 2016, Chromolaena odorata (L.) R.M. King \& H. Rob. (Asteraceae) in sub-Saharan Africa: A synthesis and review of its medicinal potential, $J$. Ethnopharmacol., 183, 112-122.

[6] Hanh, T.T.H., Hang, D.T.T., Minh, C.V., and Dat, N.T., 2011, Anti-inflammatory effects of fatty acids isolated from Chromolaena odorata, Asian Pac. J. Trop. Med., 4 (10), 760-763.

[7] Phan, T.T., Wang, L., See, P., Grayer, R.J., Chan, S.Y., and Lee, S.T., 2001, Phenolic compounds of Chromolaena odorata protect cultured skin cells from oxidative damage: Implication for cutaneous wound healing, Biol. Pharm. Bull., 24 (12), 13731379.

[8] Lu, X., Wang, J., Al-Qadiri, H.M., Ross, C.F., Powers, J., Tang, J., and Rasco, B.A., 2011, 
Determination of total phenolic content and antioxidant capacity of onion (Allium cepa) and shallot (Allium oschaninii) using infrared spectroscopy, Food Chem., 129 (2), 637-644.

[9] Hanphanphoom, S., and Krajangsang, S., 2016, Antimicrobial activity of Chromolaena odorata extracts against bacterial human skin infections, Mod. Appl. Sci., 10 (2), 159-171.

[10] Vijayaraghavan, K., Rajkumar, J., and Seyed, M.A., 2017, Efficacy of Chromolaena odorata leaf extracts for the healing of rat excision wounds, Vet. Med., 62 (10), 565-578.

[11] Azwanida, N.N., 2015, A review on the extraction methods use in medicinal plants, principle, strength, and limitation, Med. Aromat. Plants, 4 (3), 3-8.

[12] Dahmoune, F., Spigno, G., Moussi, K., Remini, H., Cherbal, A., and Madani, K., 2014, Pistacia lentiscus leaves as a source of phenolic compounds: Microwave-assisted extraction optimized and compared with ultrasound-assisted and conventional solvent extraction, Ind. Crops Prod., 61, 31-40.

[13] Alara, O.R., Abdurahman, N.H., and Olalere, O.A., 2017, Ethanolic extraction of flavonoids, phenolics and antioxidants from Vernonia amygdalina leaf using two-level factorial design, J. King Saud Univ. Sci., In Press.

[14] Alara, O.R., Abdurahman, N.H., Ukaegbu, C.I., and Azhari, N.H., 2018, Vernonia cinerea leaves as the source of phenolic compounds, antioxidants, and anti-diabetic activity using microwave-assisted extraction technique, Ind. Crop. Prod., 122, 533-544.

[15] Alara, O.R., Abdurahman, N.H., and Ukaegbu, C.I., 2017, Soxhlet extraction of phenolic compunds from Vernonia cinerea leaves and its antioxidant activity,
J. Appl. Res. Med. Aromat. Plants, 11, 12-17.

[16] Chew, K.K., Khoo, M.Z., Ng, S.Y., Thoo, Y.Y., Aida, W.M.W., and Ho, C.W., 2011, Effect of ethanol concentration, extraction time and extraction temperature on the recovery of phenolic compounds and antioxidant capacity of Orthosiphon stamineus extracts, Int. Food Res. J., 18 (4), 1427-1435.

[17] Dahmoune, F., Nayak, B., Moussi, K., Remini, H., and Madani, K., 2015, Optimization of microwaveassisted extraction of polyphenols from Myrtus communis L. leaves, Food Chem., 166, 585-595.

[18] Bouterfas, K., Mehdadi, Z., Benmansour, D., and Khaled, M.B., 2014, Optimization of extraction conditions of some phenolic compounds from white horehound (Marrubium vulgare L.) leaves, Int. J. Org. Chem., 4 (5), 292-308.

[19] Ameer, K., Bae, S.W., Jo, Y., Lee, H.G., Ameer, A., and Kwon, J.H., 2017, Optimization of microwaveassisted extraction of total extract, stevioside and rebaudioside-A from Stevia rebaudiana (Bertoni) leaves, using response surface methodology (RSM) and artificial neural network (ANN) modelling, Food Chem., 229, 198-207.

[20] Do, Q.D., Angkawijaya, A.E., Tran-Nguyen, P.L., Huynh, L.H., Soetaredjo, F.E., Ismadji, S., and Ju, Y.H., 2014, Effect of extraction solvent on total phenol content, total flavonoid content, and antioxidant activity of Limnophila aromatica, J. Food Drug Anal., 22 (3), 296-302.

[21] Xiong, Y., Rao, L., Xiong, L., Ai, Q., and Wu, X., 2012, Effects of extraction solvent on polyphenolic contents and antioxidant activities of Osmanthus fragrans' seed, Proc. Int. Conf. Biomed. Eng. Biotechnol., 217-220. 